\title{
PERTUMBUHAN DAN HASIL UBI JALAR DENGAN PEMBERIAN PUPUK KANDANG SERTA UJI VARIETAS TERHADAP CYLAS FORMICARIUS
}

\author{
Fida Azizah ${ }^{1)}$, Ato Sulistyo ${ }^{2)}$, Subagiya ${ }^{2)}$ \\ 1) Mahasiswa S1 Program Studi Agroteknologi, Fakultas Pertanian, Universitas Sebelas Maret \\ 2) Staf Dosen Program Studi Agroteknologi, Fakultas Pertanian, Universitas Sebelas Maret
}

Author Contact: fidaazizah.fa@gmail.com

\begin{abstract}
The efforts of production enhancement of sweet potato are limited by some constraints including some pest. One of the important pests is sweet potato weevil (Cylas formicarius Fabr.). The use fertilizer and kind of variety are important factors determining the yield of sweet potato. This study aims to examine the effect of manure on three varities of sweet potato and evaluate the yield of varieties test on sweet potato weevil, through choice test and no choice test. The research in field used Randomized Completely Block Design (RAKL) with two treatments. The varieties (Korea, Manohara, Madu) and manure (control, cow manure, chicken manure). Research in laboratory used three varieties and adult of $\mathrm{C}$. formicarius. The result showed that granting of chicken manure on Manohara varieties gave the best response on a length of stem, number of leaves, fresh weight and weight of tubers. Granting of cow manure on Manohara and Madu Varieties give the weight of tuber stricken was less than Korea varieties. Choice test in Manohara varieties show the high population and in no choice test show Korea Varieties had high population of $\mathrm{C}$. formicarius.
\end{abstract}

Keywords: Choice Test, No Choice Test, Tuber Characteristics, Life Cycle

AGROTECHNOLOGY RESEARCH JOURNAL

Azizah F, Sulistyo A, Subagiya. 2018. Pertumbuhan dan hasil ubi jalar dengan pemberian pupuk kandang serta uji varietas terhadap Cylas formicarius. Agrotech Res J 2(1): 22-27.

Azizah F, Sulistyo A, Subagiya. 2018. Growth and yield of sweet potato with application of manure and test varieties against Cylas formicarius. Agrotech Res J 2(1): 22-27.

\section{PENDAHULUAN}

Ubi jalar merupakan komoditas pangan yang memegang peran penting karena memiliki banyak manfaat dan nilai tambah. Peningkatan produksinya dibatasi oleh kendala di antaranya serangan hama boleng dan penggunaan pupuk kimia secara terus menerus. Serangan hama boleng (Cylas formicarius Fabr.) dapat menurunkan kualitas dan kuantitas produksi ubi jalar. Penggunaan varietas dengan mengetahui kesukaan hama terhadap suatu umbi dapat menjadi salah satu solusi pengendalian. Menurut Supriyatin (2001), larva yang menggerek umbi menyebabkan lubang di sekitar gerekan umbi menjad lebih gelap dan membusuk. Umbi tersebut menjadi tidak layak di konsumsi karena akan mempengaruhi kerja hati dan paru-paru manusia.

Selain itu penggunaan pupuk kimia dalam penanaman ubi jalar secara terus menerus berpengaruh pada pencemaran tanah, populasi mikroorganisme, dan penipisan unsur-unsur mikro. Oleh karena itu perlunya beralih dari pupuk kimia ke pupuk organik berupa pupuk kandang dapat menjadi salah satu alternatif yang dapat dilakukan. Pupuk kandang sapi dapat meningkatkan permeabilitas dan kandungan bahan organik dalam tanah, mengecilkan nilai erodibilitas tanah yang dapat meningkatkan ketahanan tanah terhadap erosi. Pupuk kandang ayam memberikan unsur hara yang mampu mencukupi pertumbuhan bibit tanaman karena unsur hara pada pupuk ini lebih tinggi daripada pupuk kandang lainnya (Magagula et al. 2010).

Penelitian ini bertujuan untuk mengkaji pengaruh pemberian pupuk kandang terhadap tiga varietas ubi jalar dan mengetahui hasil uji varietas terhadap hama boleng melalui choice test dan no choice test. Manfaat dari penelitian ini yaitu memberikan informasi respon tiga varietas ubi jalar dengan pemberian pupuk kandang dan hasil uji varietas melalui choice test dan no choice test.

\section{BAHAN DAN METODE}

Penelitian dilaksanakan dua tahap yaitu di Lahan Pertanian Desa Karangbangun, Kecamatan Matesih Kabupaten Karanganyar mulai bulan September 2016Januari 2017 dan di Laboratorium Hama dan Penyakit FP UNS bulan Juni-September 2017.

Alat yang digunakan di Lapang antara lain cangkul, meteran, ember, papan nama, timbangan analitik. Sementara di Laboratorium menggunakan mikroskop binokuler, toples, petridish, cutter, solasi, botol plastik. Bahan yang digunakan di lapang berupa stek pucuk ubi jalar varietas Korea, Manohara, Madu, pupuk kandang sapi, dan pupuk kandang ayam sementara bahan yang digunakan di Laboratorium berupa ubi jalar varietas Korea, Manohara, Madu yang didapat dari pasar-pasar sekitar Surakarta dan stok imago hama boleng. Pelaksanaan penelitian di Lapang berupa persiapan lahan, pemupukan, penanaman, pemeliharaan, pemanenan dan di Laboratorium yaitu perbanyakan hama boleng, pengamatan mikroskop, dan infestasi hama boleng pada choice test dan no choice test.

Penelitian di Lapang menggunakan Rancangan

${ }^{*}$ Fak. Pertanian UNS Surakarta

JI. Ir. Sutami 36 A Surakarta

Pertumbuhan dan Hasil Ubi Jalar dengan Pemberian Pupuk Kandang serta Uji Varietas Terhadap Cylas

formicarius.(Fida Azizah, Ato Sulistyo, Subagya) 
Acak Kelompok lengkap (RAKL) dengan 2 faktor perlakuan yaitu varietas dan pupuk. Varietas yang digunakan yaitu Korea (V1), Manohara (V2), dan Madu (V3). Pupuk yang diaplikasikan yaitu kontrol (P0), pupuk kandang sapi (P1), dan pupuk kandang ayam (P2). Pupuk yang digunakan sebanyak $12,5 \mathrm{Kg} / \mathrm{m}^{2}$. Terdapat 9 kombinasi perlakuan yaitu V1P0, V1P1, V1P2, V2P0, V2P1, V2P2, V3P0, V3P1, V3P2. Masingmasing perlakuan diulang sebanyak 3 ulangan sehingga terdapat 27 petak penelitian.

Penelitian di Laboratorium menggunakan choice test dan no choice test. Choice test dilaksanakan dengan menaruh 3 ubi jalar dari masing-masing varietas pada satu wadah tertutup kemudian di infestasikan imago sebanyak 5 pasang selama 5 hari, kemudian imago dikeluarkan saat hari ke- 6 dan diinkubasi selama 40 hari. Sementara no choice test dilakukan dengan menaruh 3 varietas ubi jalar pada wadah yang berbeda dan diinfestasikan 2 pasang imago selama 5 hari, dan cara selanjutnya sama seperti choice test. Hasil pengamatan di Lapang dianalisis dengan analisis ragam dan DMRT taraf $5 \%$, sementara hasil di Laboratorium dianalisis dengan Microsoft Excel.

\section{HASIL DAN PEMBAHASAN}

\section{Kondisi umum lokasi penelitian}

Penelitian dilaksanakan di lahan pertanian Desa Karangbangun, Kecamatan Matesih Kabupaten Karanganyar. Lokasi penelitian terletak pada koordinat $7^{\circ} 32$ ' 38,6" LS dan $111^{\circ} 33^{\prime} 46,8^{\prime \prime}$ BT. Lahan pertanian di Kecamatan Matesih didominasi oleh petani yang menanam ubi jalar sistem tumpang sari dengan tanaman kembang kol. Selain itu banyak juga lahan yang ditanami melon, timun, dan cabai. Beberapa varietas ubi jalar yang biasa ditanam ialah varietas Rami, Remis, Ungu, Madu, Jepang, Korea, Manohara.

Penelitian di Laboratorium dilaksanakan dengan mengumpulkan ubi jalar yang sehat dan terserang dari pasar-pasar sekitar Surakarta. Hama boleng didapat dari ubi yang terserang dan dibawa ke Laboratorium untuk diamati jenisnya di bawah mikroskop.

\section{Panjang batang}

Tabel 1 menunjukkan bahwa pemberian pupuk terhadap panjang batang tidak berbeda nyata antara ketiganya. Sementara varietas menunjukkan hasil yang berbeda nyata. Varietas Manohara menunjukkan kecenderungan panjang batang tertinggi yaitu 162.53 $\mathrm{cm} /$ tanaman. Pemberian pupuk kandang ayam menunjukkan kecenderungan panjang batang lebih tinggi dari aplikasi pupuk lainnya. Rata-rata panjang batang dengan aplikasi pupuk kandang ayam sebesar $153 \mathrm{~cm} /$ tanaman. Pupuk kandang ayam diduga memiliki unsur nitrogen yang lebih tinggi dibanding pupuk kandang sapi. Sowley et al. (2015) menyatakan bahwa pemberian pupuk kandang ayam memberikan hasil yang nyata terhadap batang ubi jalar kuning pada 10, 12, dan 14 MST dibanding pemberian NPK. Hal ini dapat disebabkan karena kandungan $\mathrm{N}$ yang tinggi pada pupuk kandang ayam dan dapat menyuplai unsur $\mathrm{N}$ dalam waktu yang lebih lama.
Tabel 1 Kombinasi perlakuan terhadap panjang batang (cm/tanaman)

\begin{tabular}{llllc}
\hline Varietas & \multicolumn{3}{c}{ Pupuk } & $\begin{array}{c}\text { Rata- } \\
\text { rata }\end{array}$ \\
\cline { 2 - 4 } & Kontrol & Sapi & Ayam & \\
\hline Korea & $109,17 \mathrm{a}$ & $108,88 \mathrm{a}$ & $110,63 \mathrm{a}$ & $109,56 \mathrm{a}$ \\
Manohara & $144,25 \mathrm{~b}$ & $157,29 \mathrm{~b}$ & $186,04 \mathrm{a}$ & $162,53 \mathrm{c}$ \\
Madu & $134,96 \mathrm{~b}$ & $137,04 \mathrm{~b}$ & $162,33 \mathrm{a}$ & $144,78 \mathrm{~b}$ \\
\hline Rata-rata & $129,46 \mathrm{a}$ & $134,40 \mathrm{a}$ & $153,00 \mathrm{a}$ & \\
\hline
\end{tabular}

Keterangan: Angka yang diikuti huruf yang sama menunjukkan tidak beda nyata pada uji Duncan taraf $5 \%$

\section{Jumlah cabang primer}

Tabel 2 menunjukkan bahwa perlakuan pupuk dan perbedaan varietas tidak memberikan pengaruh yang nyata terhadap jumlah cabang primer. Hal ini diduga karena genetik tanaman lebih mempengaruhi pertumbuhan daripada pemberian pupuk. Menurut Zelalem et al. (2009), jumlah batang tanaman kentang tidak signifikan terhadap pemupukan. Hal ini terjadi karena sifat dari tanaman lebih mempengaruhi terhadap karakter yang melekat pada tanaman daripada pemberian pupuk. Jumlah batang dapat dipengaruhi oleh faktor lain seperti kondisi penyimpanan umbi, potensi genetik kultivar, kerusakan tunas saat tanam dan kondisi pertumbuhan.

Namun rata-rata cabang primer menunjukkan bahwa pupuk kandang ayam memberikan hasil tertinggi sebesar 3 cabang/tanaman. Menurut Sumarwoto et al. (2008), pemberian pupuk kandang ayam mampu memberikan pertumbuhan jumlah cabang paling tinggi pada ubi jalar. Hal ini disebabkan selain pupuk kandang dapat memberikan unsur hara, juga dapat memperbaiki aerasi tanah. Sementara varietas Madu memberikan respon cabang primer tertinggi yaitu 3,11 cabang/tanaman.

Tabel 2 Kombinasi perlakuan terhadap jumlah cabang primer (buah/tanaman)

\begin{tabular}{lrrrl}
\hline \multirow{2}{*}{ Varietas } & \multicolumn{3}{c}{ Pupuk } & \multirow{2}{*}{ Rata-rata } \\
\cline { 2 - 4 } & Kontrol & Sapi & Ayam & \\
\hline Korea & $2,25 \mathrm{a}$ & $2,75 \mathrm{~b}$ & $2,42 \mathrm{a}$ & $2,47 \mathrm{a}$ \\
Manohara & $2,25 \mathrm{~b}$ & $3,08 \mathrm{~b}$ & $3,42 \mathrm{a}$ & $2,92 \mathrm{a}$ \\
Madu & $3,17 \mathrm{a}$ & $3 \mathrm{a}$ & $3,17 \mathrm{a}$ & $3,11 \mathrm{a}$ \\
\hline Rata-rata & $2,56 \mathrm{a}$ & $2,94 \mathrm{a}$ & $3,00 \mathrm{a}$ & \\
\hline
\end{tabular}

Keterangan: Angka yang diikuti huruf yang sama menunjukkan tidak beda nyata pada uji Duncan taraf $5 \%$

\section{Jumlah daun}

Tabel 3 menunjukkan bahwa helai daun yang terbentuk pada varietas Manohara lebih banyak sebesar 122,67 helai/tanaman. Hal ini disebabkan karena panjang batang varietas tersebut lebih tinggi. Hasil penelitian oleh Salawu dan Mukhtar (2008) menyatakan bahwa jumlah cabang berkorelasi positif dengan panjang batang ubi jalar. Panjang batang 
berkorelasi positif dengan jumlah daun saat panen. Varietas Manohara memiliki panjang batang lebih panjang sehingga kemungkinan jumlah daun pun lebih banyak.

Pemupukan dengan pupuk kandang ayam memberikan helai daun lebih banyak sebesar 112.58 helai/tanaman (Tabel 3). Hal tersebut sesuai dengan penelitian oleh Estiaty et al. (2005), bahwa penambahan pupuk kandang ayam memberikan pertumbuhan yang lebih tinggi daripada pupuk kandang sapi pada tanaman kangkung (Ipomoea reptans). Hal ini disebabkan pupuk kandang kotoran ayam mempunyai kandungan $\mathrm{N}, \mathrm{P}, \mathrm{K}, \mathrm{Ca}$, dan $\mathrm{Mg}$ lebih tinggi dibandingkan dengan pupuk kandang kotoran sapi.

Tabel 3 Kombinasi perlakuan terhadap jumlah daun (helai/tanaman)

\begin{tabular}{lrrrr}
\hline \multirow{2}{*}{ Varietas } & \multicolumn{3}{c}{ Pupuk } & \multirow{2}{*}{ Rata-rata } \\
\cline { 2 - 4 } & Kontrol & Sapi & Ayam & \\
\hline Korea & $87,92 \mathrm{a}$ & $77,83 \mathrm{a}$ & $86,17 \mathrm{a}$ & $83,97 \mathrm{a}$ \\
Manohara & $122,17 \mathrm{~b}$ & $114,58 \mathrm{~b}$ & $131,25 \mathrm{a}$ & $122,67 \mathrm{~b}$ \\
Madu & $91,33 \mathrm{~b}$ & $105 \mathrm{~b}$ & $120,33 \mathrm{a}$ & $105,55 \mathrm{~b}$ \\
\cline { 1 - 4 } Rata-rata & $100,47 \mathrm{a}$ & $99,14 \mathrm{a}$ & $112,58 \mathrm{a}$ &
\end{tabular}

Keterangan: Angka yang diikuti huruf yang sama menunjukkan tidak beda nyata pada uji Duncan taraf $5 \%$

\section{Berat segar brangkasan}

Tabel 4 menunjukkan bahwa perlakuan varietas dan pupuk tidak memberikan pengaruh nyata terhadap berat segar brangkasan. Namun rata-rata pemberian pupuk menunjukkan pupuk kandang sapi menghasilkan berat segar brangkasan tertinggi. Hal ini diduga karena tanaman mampu menyerap unsur hara dan air lebih banyak dibanding perlakuan lainnya. Menurut penelitian Utami dan Rachmawati (2016), pemberian pupuk organik dengan berbagai dosis menghasilkan berat basah yang lebih tinggi dibandingkan dengan tanpa pupuk organik pada tanaman kangkung darat ( $I$. reptans). Peningkatan berat basah tidak terlepas dari peningkatan unsur hara seperti nitrogen, fosfor, dan kalium.

Tabel 4 Kombinasi perlakuan terhadap berat segar brangkasan (g/tanaman)

\begin{tabular}{lrrrr}
\hline \multirow{2}{*}{ Varietas } & \multicolumn{3}{c}{ Pupuk } & \multirow{2}{*}{ Rata-rata } \\
\cline { 2 - 4 } & Kontrol & Sapi & Ayam & \\
\hline Korea & $821,42 a$ & $830,96 a$ & $812,01 a$ & $821,46 a$ \\
Manohara & $837,46 a$ & $838,71 a$ & $838,83 a$ & $838,33 a$ \\
Madu & $836,17 a$ & $832,71 b$ & $835,25 a$ & $834,71 a$ \\
\hline Rata-rata & $831,68 a$ & $834,13 a$ & $828,70 a$ &
\end{tabular}

Keterangan: Angka yang diikuti huruf yang sama menunjukkan tidak beda nyata pada uji Duncan taraf $5 \%$

Sementara perbedaan varietas menunjukkan bahwa varietas Manohara menghasilkan berat segar brangkasan tertinggi sebesar $838.33 \mathrm{~g} /$ tanaman. Hal ini tidak terlepas dari parameter pertumbuhan yaitu panjang batang dan jumlah daun yang dimiliki oleh varietas Manohara lebih tinggi dibanding varietas lainnya. Menurut Indria (2005), jumlah dan ukuran tajuk akan mempengaruhi berat brangkasan. Semakin banyak jumlah daun dan semakin tinggi tanaman maka berat brangkasan segar akan semakin besar.

\section{Berat kering brangkasan}

Perbedaan varietas dan perlakuan pupuk tidak memberikan pengaruh yang nyata terhadap berat kering brangkasan (Tabel 5). Namun rata-rata pemberian pupuk kandang sapi menunjukkan hasil tertinggi sebesar $192.21 \mathrm{~g} /$ tanaman. Berat kering brangkasan erat hubungannya dengan proses penyerapan hara untuk meningkatkan pertumbuhan saat fase vegetatif dan perkembangan fase generatif. Hasil penelitian oleh Jedeng (2011) menyebutkan bahwa tanaman ubi jalar tanpa perlakuan pupuk ( 0 ton $\mathrm{ha}^{-1}$ ) menunjukkan berat kering brangkasan terendah sementara berat berat kering brangkasan dengan pupuk kandang sapi menunjukkan hasil yang tinggi. Hal ini disebabkan oleh terbatasnya unsur hara yang tersedia untuk tanaman tanpa perlakuan pupuk sehingga pertumbuhan dan perkembangan tanaman terhambat atau tidak optimal. Sementara varietas Madu menunjukkan berat kering brangkasan tertinggi sebesar $192.76 \mathrm{~g} /$ tanaman (Tabel 5).

Tabel 5 Kombinasi perlakuan terhadap berat kering brangkasan (g/tanaman)

\begin{tabular}{lllll}
\hline \multirow{2}{*}{ Varietas } & \multicolumn{3}{c}{ Pupuk } & $\begin{array}{c}\text { Rata- } \\
\text { rata }\end{array}$ \\
\cline { 2 - 4 } & Kontrol & Sapi & Ayam & $186,47 a$ \\
Korea & $184,15 \mathrm{~b}$ & $190,77 \mathrm{a}$ & $184,49 \mathrm{~b}$ & $182,60 \mathrm{a}$ \\
Manohara & $190,74 \mathrm{a}$ & $193,04 \mathrm{a}$ & $194,03 \mathrm{a}$ & $192,60 \mathrm{a}$ \\
Madu & $192,21 \mathrm{a}$ & $192,82 \mathrm{a}$ & $193,26 \mathrm{a}$ & $192,76 \mathrm{a}$ \\
\cline { 1 - 4 } Rata-rata & $189,03 \mathrm{a}$ & $192,21 \mathrm{a}$ & $190,10 \mathrm{a}$ &
\end{tabular}

Keterangan: Angka yang diikuti huruf yang sama menunjukkan tidak beda nyata pada uji Duncan taraf $5 \%$

\section{Bobot umbi total}

Perlakuan varietas dan pupuk tidak memberikan pengaruh yang nyata terhadap bobot umbi (Tabel 6). Hal ini diduga karena dosis pupuk kandang belum mencukupi untuk mendorong fase generatif tanaman. namun rata-rata pemberian pupuk menunjukkan bahwa pupuk kandang ayam memberikan bobot umbi tertinggi kemudian diikuti dengan pupuk kandang sapi. Hasil penelitian oleh Yoandari et al. (2017), pemberian pupuk kandang ayam berpengaruh terhadap bobot total umbi. Rataan bobot umbi tertinggi dihasilkan oleh pupuk kandang ayam sampai dosis 15 ton ha ${ }^{-1}$. Sementara itu menurut Haliru et al. (2015) pemberian pupuk kandang sapi memberikan hasil yang signifikan terhadap komponen hasil ubi jalar. $\mathrm{Hal}$ ini disebabkan keberadaan unsur hara kalium yang tinggi pada pupuk kandang sapi mampu memperlihatkan bobot umbi yang lebih tinggi. Tersedianya unsur kalium yang cukup bagi 
tanaman ubi jalar menyebabkan proses pembentukan karbohidrat dan translokasinya ke umbi berjalan lancar.

Tabel 6 Kombinasi perlakuan terhadap bobot umbi total (g/tanaman)

\begin{tabular}{lrrrr}
\hline Varietas & \multicolumn{3}{c}{ Pupuk } & $\begin{array}{c}\text { Rata- } \\
\text { rata }\end{array}$ \\
\cline { 2 - 4 } & Kontrol & Sapi & Ayam & Ky, \\
\hline Korea & $484,58 \mathrm{a}$ & $598,33 \mathrm{~b}$ & $642,92 \mathrm{~b}$ & $575,28 \mathrm{a}$ \\
Manohara & $640,42 \mathrm{~b}$ & $794,58 \mathrm{a}$ & $640,83 \mathrm{~b}$ & $691,94 \mathrm{a}$ \\
Madu & $466,67 \mathrm{a}$ & $405,83 \mathrm{a}$ & $777,92 \mathrm{~b}$ & $550,14 \mathrm{a}$ \\
\hline Rata-rata & $530,55 \mathrm{a}$ & $599,58 \mathrm{a}$ & $687,22 \mathrm{a}$ &
\end{tabular}

Keterangan: Angka yang diikuti huruf yang sama menunjukkan tidak beda nyata pada uji Duncan taraf $5 \%$

Tabel 6 menunjukkan rata-rata bobot umbi total varietas Manohara memberikan hasil tertinggi sebesar 691,94 g/tanaman. Hal ini disebabkan karena komponen pertumbuhan berupa jumlah daun pada varietas Manohara menunjukkan hasil yang lebih baik. Jumlah daun akan mempengaruhi proses fotosintesis karena jumlah daun yang banyak membuat tanaman mampu berfotosintesis optimal dibandingkan dengan jumlah daun yang sedikit.

\section{Bobot umbi terserang}

Perbedaan varietas menunjukkan hasil yang beda nyata terhadap bobot umbi terserang (Tabel 7). Varietas Manohara memberikan bobot umbi terserang oleh hama boleng paling tinggi disebabkan ukuran umbi yang lebih besar dibandingkan varietas lainnya sehingga kemungkinan terserang juga lebih besar. Adapun setiap perlakuan memiliki peluang untuk terserang oleh hama boleng, tetapi tingkat serangannnya berbeda-beda.

Tabel 7 Kombinasi perlakuan terhadap bobot umbi terserang (g/tanaman)

\begin{tabular}{|c|c|c|c|c|}
\hline \multirow{2}{*}{ Varietas } & \multicolumn{3}{|c|}{ Pupuk } & \multirow{2}{*}{$\begin{array}{l}\text { Rata- } \\
\text { rata }\end{array}$} \\
\hline & Kontrol & Sapi & Ayam & \\
\hline Kore & $212,50 a$ & $139,58 b$ & $110 \mathrm{~b}$ & $154,03 b$ \\
\hline Manohara & $266,25 a$ & $140,42 a$ & $182,08 a$ & $196,25 b$ \\
\hline Madu & $153,75 a$ & $107,08 a$ & $127,92 \mathrm{a}$ & 129,58 \\
\hline Rata-rata & $210,83 a$ & $129,03 a$ & $140 a$ & \\
\hline
\end{tabular}

Keterangan: Angka yang diikuti huruf yang sama menunjukkan tidak beda nyata pada uji Duncan taraf $5 \%$

Sementara rata-rata pemberian pupuk menunjukkan pupuk kandang sapi memberikan bobot umbi terserang paling rendah sebesar 129,03 g/tanaman (Tabel 7). Hal ini diduga karena unsur kalium yang cukup pada pupuk kandang sapi berperan untuk meningkatkan mutu hasil. Menurut Patil (2011), kalium mempunyai fungsi memperbaiki pertumbuhan tanaman, meningkatkan ketahanan terhadap penyakit dan memperbaiki mutu hasil.

\section{Choice test}

\section{Populasi}

Gambar 1 menunjukkan varietas Korea mencapai puncak populasi pada hari ke 38 sebelum ubi dibelah sebanyak 5 imago. Saat hari ke 40 ubi dibelah jumlah imago paling tinggi pada varietas Korea yaitu 12 imago. Varietas Manohara mencapai puncak populasi pada hari ke 27 setelah infestasi sebanyak 7 imago. Pada hari setelahnya, terjadi penurunan dan kenaikan yang fluktuatif. Sementara pada varietas Madu puncak populasi terjadi hari ke 26 setelah infestasi yaitu 3 imago. Menurut Eliza (2014), imago yang muncul sangat erat hubungannya dengan perilaku makan larva. Semakin banyak imago yang muncul pada setiap bahan uji maka semakin besar pula kesukaan larva terhadap bahan uji tersebut.

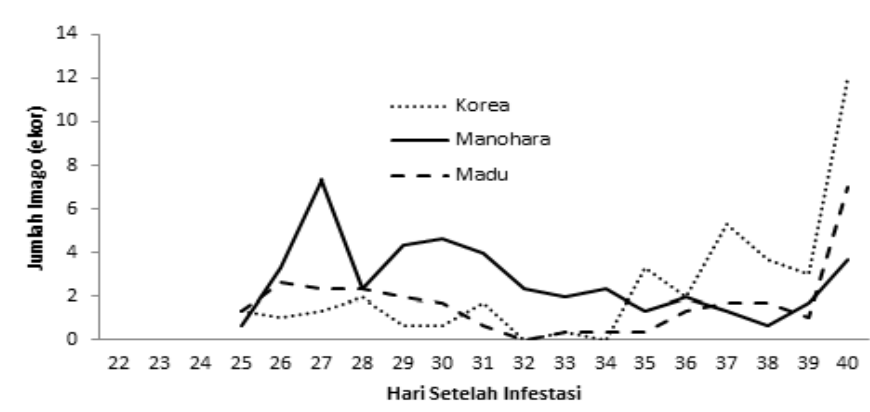

Gambar 1 Populasi imago pada choice test

\section{Jumlah larva, pupa, dan imago}

Varietas Manohara menghasilkan jumlah imago tertinggi sebesar 132 ekor (Tabel 8). Hasil penelitian Kosala (2016), ubi yang memiliki warna dan daging ubi berwarna ungu dan putih memiliki tingkat terserang hama $C$. formicarius cukup tinggi yaitu $20-65 \%$ pada varietas Bogor (kulit ungu, daging putih) dan $60 \%$ pada varietas Jepang (kulit putih, daging putih). Tabel 8 menunjukkan populasi imago pada ketiga varietas lebih tinggi daripada populasi larva dan pupa. Berkembangnya populasi imago yang tinggi disebabkan karena jenis ubi yang ditempati sesuai untuk menyelesaikan siklus hidupnya sehingga jumlah larva dan pupa yang belum menyelesaikan stadiumnya tinggal sedikit.

Tabel 8 Populasi stadium C. formicarius pada choice test

\begin{tabular}{lccc}
\hline Varietas & Larva & Pupa & Imago \\
\hline Korea & 7 & 26 & 115 \\
Manohara & 10 & 16 & 132 \\
Madu & 12 & 15 & 80 \\
\hline
\end{tabular}

\section{No choice test}

\section{Populasi}

Gambar 2 menunjukkan puncak populasi yang terjadi pada varietas Korea yaitu pada hari ke 36 sebanyak 6 ekor kemudian menurun sampai hari ke 40. Sementara rata-rata imago pada varietas Manohara 
setelah infestasi berjumlah 1-2 ekor. Pada varietas Madu imago paling tinggi keluar saat hari ke 34 dan 36 setelah infestasi sebanyak 3 ekor. Rata-rata imago yang keluar pada varietas Korea lebih tinggi dari varietas lainnya. Hal ini dapat terjadi diduga karena karakteristik umbi pada varietas Korea yang memiliki kulit umbi lebih tipis membuat imago betina mudah bertelur di dalamnya. Menurut Mauludiana et al. (2015), kulit umbi yang tebal dan kadar air yang rendah menyebabkan dewasa $C$. formicarius kesulitan makan dan meletakkan telur. Hal tersebut dapat memberikan pengaruh terhadap populasi dewasa $C$. formicarius pada ubi jalar.

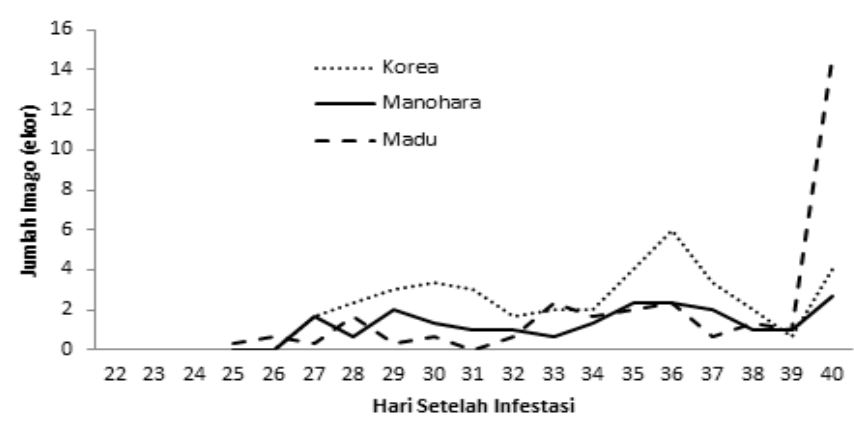

Gambar 2 Populasi imago pada no choice test

\section{Jumlah larva, pupa, dan imago}

Tabel 9 menunjukkan varietas Korea menghasilkan imago tertinggi sebanyak 117 ekor. Daging umbi varietas Korea yang berwarna oranye mengandung senyawa penting yaitu karotenoid. Komponen utama karotenoid pada ubi jalar adalah ß-karoten (86-90\%). Ciri khas dari ubi jalar yang memiliki kadar karoten tinggi adalah kadar airnya tinggi dan bahan keringnya rendah $(<30 \%)$ (Yamakawa 1998). Sementara menurut Mauludiana et al (2015), kadar air yang rendah menyebabkan dewasa $C$. formicarius kesulitan untuk makan dan meletakkan telur. Sehingga kemungkinan kadar air yang dimiliki oleh varietas Korea tinggi sehingga imago $C$. formicarius suka untuk makan dan meletakkan telur.

Tabel 9 Populasi stadium C. formicarius pada no choice test

\begin{tabular}{llll}
\hline Varietas & Larva & Pupa & Imago \\
\hline Korea & 7 & 46 & 117 \\
Manohara & 0 & 0 & 63 \\
Madu & 19 & 21 & 90 \\
\hline
\end{tabular}

Varietas Manohara saat hari ke 40 dibelah tidak menunjukkan adanya larva dan pupa (tabel 9). Hal ini diduga karena siklus hama ini sudah melewati stadium larva dan pupa sehingga yang tersisa saat dibelah tinggal imagonya saja. Menurut Sherman dan Tamashiro (1954), larva dapat makan di dalam akar atau batang tempat terjadinya oviposisi dan melangsungkan siklus selama 25-35 hari untuk menyelesaikan 3 instar. Mullen (1981), mengemukakan durasi pupa masing-masing berkisar 5-10.7 hari pada 25 dan $20^{\circ} \mathrm{C}$.

\section{KESIMPULAN DAN SARAN}

\section{Kesimpulan}

Berdasarkan hasil penelitian pertumbuhan dan hasil ubi jalar dengan pemberian pupuk kandang serta uji varietas terhadap Cylas formicarius, dapat disimpulkan bahwa:

1. Pemberian pupuk kandang ayam memberikan respon paling baik untuk varietas Manohara pada variabel penelitian panjang batang yaitu 162.53 cm/tanaman, jumlah daun sebesar 122.67 helai/tanaman, berat segar brangkasan sebesar $838.33 \mathrm{~g} /$ tanaman, dan bobot umbi total sebesar $691.94 \mathrm{~g} /$ tanaman

2. Pemberian pupuk kandang sapi pada varietas Manohara dan Madu menghasilkan bobot umbi terserang paling rendah masing-masing sebesar $140.42 \mathrm{~g} /$ tanaman dan $107.08 \mathrm{~g} /$ tanaman

3. Choice test pada varietas Manohara menghasilkan populasi yaitu 10 larva, 16 pupa, dan 132 imago sementara varietas Madu menghasilkan populasi yaitu 12 larva, 15 pupa, dan 80 imago

4. No choice test pada varietas Korea menghasilkan populasi yaitu 7 larva, 46 pupa, dan 117 imago sementara varietas Manohara menghasilkan populasi 90 imago tanpa kehadiran larva dan pupa

\section{Saran}

Saran yang dapat diberikan untuk penelitian ini yaitu perlunya menghitung jumlah umbi tiap tanaman sampel untuk mengetahui beratnya kerusakan yang disebabkan oleh hama dan penambahan dosis pupuk kandang agar hasilnya dapat signifikan

\section{DAFTAR PUSTAKA}

Eliza TD. 2014. Kesesuaian lima jenis komoditas pascapanen sebagai media perkembangbiakan hama gudang ephestia cautella (walker) (Lepidoptera : Pyralidae). Skripsi. Institut Pertanian Bogor

Estiaty LM, Suwardi, Yuliana I, Fatimah D, Suherman D. 2005. Pengaruh zeolite terhadap efisiensi unsur hara pada pupuk kandang dalam tanah. J Zeolit Indonesia. 4(2): 62-69

Haliru M, Dikko AU, Audu M, Aliyu I. 2015. Effect of cow dung on soil properties and performance of sweet potato (Ipomoea batatas L.) in Sudan Savanna Nigeria. J of plant and soil science. 5 (4): 212-216

Indria AT. 2005. Pengaruh sistem pengolahan tanah dan pemberian macam bahan organik terhadap pertumbuhan dan hasil kacang tanah (Arachis hypogaea L.). Skripsi. Universitas Sebelas Maret.

Jedeng IW. 2011. Pengaruh macam dan dosis pupuk organik terhadap pertumbuhan dan hasil ubi jalar (Ipomoea batatas (I.) Lamb.) var lokal ungu. Tesis. Universitas Andalas.

Kosala R. 2016. Hubungan faktor agroekosistem terhadap serangan hama Cylas formicarius pada ubi jalar. Skripsi. Universitas Sebelas Maret 
Magagula NEM, Ossom EM, Rhykerd RL, Rhykerd CL. 2010. Chicken manure affects sweetpotato [Ipomoea batatas(L.) Lam] nutrient element concentration in tubers and leaves in Swaziland. J Agric Food Tech. 1(1):8-16

Mauludiana S, Pantja LA, Himawan T. 2015. Kepekaan beberapa varietas ubi jalar (Ipomoea batatas (L.) Lam.) terhadap hama Cylas formicarius Fabricius (Coleoptera: Curculionidae). J HPT. 3(1): 54-60

Mullen MA. 1981. Sweetpotato weevil, Cylas formicarius elegantulus (Summers): development, fecundity, and longevity. Annals of the Entomological Society of America. 74(5):478-481

Patil RB. 2011. Role of potassium humate on growth and yield of soybean and black gram. International $\mathrm{J}$ of Pharma and Bio Science. 2(1): 242-246

Salawu IS, Mukhtar AA. 2008. Reducing the dimension of growth and yield characters of sweet potato (Ipomoe batatas L.) varieties as affected by varying rates of organic and inorganic fertilizer. Asian $\mathrm{J}$ Agricult Res. 2(1):41-44

Sherman M, Tamashiro M. 1954. The sweet potato weevils in Hawaii, their biology and control. Hawaii agricultural experiment station technical bulletin no 23.

Sowley ENK, Neindow M, Abubakari AH. 2015. Effect of poultry manure and NPK on yield and storability of orange and white fleshed sweet potato (Ipomoea batatas (L.). J of Food and Agriculture Science. 5 (1):1-6

Sumarwoto, Wirawati T, Frisanto R. 2008. Uji varietas ubi jalar (Ipomoea batatas L.) pada berbagai jenis pupuk organik alamai dan pupuk buatan $(\mathrm{N}, \mathrm{P}$, dan K). J Pertanian Mapeta. 10 (3): 203-210.

Supriyatin. 2001. Hama boleng pada ubi jalar dan cara pengendaliannya. Buletin Palawija (2):22-29.

Utami LB, Rachmawati U. 2016. Pengaruh pemberian pupuk organik pada media tanah yang mengandung timbal $(\mathrm{Pb})$ terhadap pertumbuhan kangkung darat (Ipomoea reptans Poir.). J biologi. 20(1):6-10

Yamakawa O. 1998. Development of new cultivation and utilization system for sweet potato towards the 21st century. Proceedings of The International Workshop on Sweet Potato; Production System Towards The 21st Century, December 9-10, 1997 (D.R. LaBonte, M. Ymashita and H. Machida, eds). pp. 1-8, Kyushu National Agricultural Experiment Station, Miyakonojo, Miyazaki, Japan.

Yoandari, Rosanty RL, Rahmawati N. 2017. Respon pertumbuhan dan produksi ubi jalar (Ipomoea batatas L.) terhadap tinggi bedengan dan dosis pupuk kandang ayam. J Agroekoteknologi FP USU. $5(1): 33-41$

Zelalem A, TekalignTNi, gussie D. 2009.Response of potato (Solanum tuberosum L.) to different rates of nitrogen and phosphorus fertilization on vertisols at DebreBerhan, in the central highlands of Ethiopia. Afr. J Plant Sci. 3 (2): 16-24. 